\title{
Aggressive and Docile Colony Defence Patterns in Apis mellifera. A Retreater-Releaser Concept
}

\author{
Gerald Kastberger • Ronald Thenius • \\ Anton Stabentheiner • Randall Hepburn
}

Revised: 26 June 2008 / Accepted: 3 September 2008 /

Published online: 11 November 2008

(C) The Author(s) 2008. This article is published with open access at Springerlink.com

\begin{abstract}
Colony defence in Apis mellifera involves a variety of traits ranging from 'aggressive' (e.g. entrance guarding, recruitment of flying guards) to 'docile' (e.g. retreating into the nest) expression. We tested 11 colonies of three subspecies (capensis, scutellata, carnica) regarding their defensiveness. Each colony was selected as reportedly 'aggressive', 'intermediate' or 'docile' and consisted of about 10,000 bees. We applied three stimulation regimes (mechanical disturbance, exposure to alarm pheromones, and the combination of both) and measured their behaviours by tracking the rates of outflying bees at the entrance sites of the test hives. We provided evidence that for mechanical disturbances the test colonies resolved into two response types, if the 'immediate' defence response, assessed in the first minute of stimulation, was taken as a function of foraging: 'releaser' colonies allocated flying guards, 'retreater' colonies reduced the outside-hive activities. This division was observed irrespective of the subspecies membership and maintained in even roughly changing environmental conditions. However, if pheromone and mechanical stimulation were combined, the variety of colony defensiveness restricted to two further types irrespective of the subspecies membership: six of nine colonies degraded their rate of flying defenders with increasing foraging level, three of the colonies extended their 'aggressiveness' by increasing the defender rate with the foraging level. Such 'super-aggressive' colonies obviously are able to allocate two separate recruitment pools for foragers and flying defenders.
\end{abstract}

Keywords Defence behaviour - aggressiveness · docility · flying defenders · soldier bees $\cdot$ retreating $\cdot$ Apis mellifera

G. Kastberger $(\triangle) \cdot R$. Thenius $\cdot$ A. Stabentheiner

Department of Zoology, University of Graz, A 8010 Graz, Austria

e-mail: gerald.kastberger@uni-graz.at

R. Hepburn

Department of Zoology, Rhodes University, Grahamstown, South Africa 


\section{Introduction}

An elaborate defence system in both open-nesting (Seeley et al. 1982; Kastberger et al. 2007) and cavity dwelling species (Ruttner 1988) of honeybees has evolved in tandem with the attractiveness of honeybee colonies and their nests as food resources for predators. In particular, the honeybees have to run a cunning trading-off regarding the two poles of work loads, foraging and defending, to efficiently collect and minister the pollen and honey resources and to safeguard the nest in order to minimize losses and expenses. The main goal of defence is therefore to make the nest site a zone of shelter for colony members as well as a zone of high risk for predators for which the entry fee has to be set as high as possible.

Nonetheless, there is considerable variation in the defence systems among and within honeybee species (Kerr 1967; Winston 1992; Boch and Rothenbuhler 1974; Winston 1987; Moritz et al. 1987; Moritz and Southwick 1992; Page et al. 1995; Seeley et al. 1982), even in colonies headed by related queens kept under the same conditions in the same apiary (Collins et al. 1980, 1984, 1988; Schneider and McNally 1992; Page et al. 1995; Stort 1974, 1975a, b; Villa 1988). Generally, variability in defensiveness in honeybees is caused by internal and external factors (Schua 1952; Woyke 1992; Collins 1981; Brandeburgo et al. 1982; Southwick and Moritz 1987; Collins and Rinderer 1985; Breed et al. 2004) and ranges from extreme 'docility' to extreme 'aggressiveness'.

'Docile' strategies in honeybees can be defined as being generally non-stinging and avoiding exposure to the predator. In this context, the workers of cavitydwelling species, Apis mellifera and A. cerana, respond to some threats by reduction or even ceasing the outside-hive activities. Staying at the nest under threat has also the advantage of having a sufficiently big stock for collective defence. The phylogenetically older free-nesting Giant honeybees $A$. dorsata also exhibit 'docile' traits that effectively repel wasp predators (Kastberger et al. 2007) by colony members on the curtain surface, which stay at the nest and show synchronized abdominal shaking. In $A$. mellifera, 'docility' is reported to be associated with low ambient temperature, low ambient humidity (Schua 1952; Collins 1981; Drum and Rothenbuhler 1984), small colony size (Boch and Rothenbuhler 1974; Collins et al. 1982; Collins and Kubasek 1982), low honey store size and good nectar flows in the field (Winston 1987).

The 'aggressive' strategies of honeybees comprise guarding and soldier behaviour (Breed et al. 1990, 2004; Stabentheiner et al. 2002, 2007) in diverse facets. According to conventional terminology, guard bees patrol the entrance of the colony as well as the periphery of the nest in open colonies. The main purpose of guarding is to identify and remove foreign conspecific intruders (Breed et al. 1992). However, guard bees may also play a role in recruiting other bees to defend against larger intruders (Moore et al. 1987). Such non-guard defenders are mobilised and released particularly in masses to repel intruders in counter-attacking operations. The term "soldier bees" (Breed et al. 2004) is appropriate to designate bees that pursue or sting, although not necessarily in the sense of task specialisation. In particular, Giant honeybees (Kastberger and Sharma 2000), African bees (e.g. A. mellifera scutellata) and the Africanized bees (Collins et al. 1982; Villa 1988; Winston 1992) are notorious for ganging up a mass of stinging non-guard defenders within tens of seconds. 
In this paper, we focused on the responsiveness of $A$. mellifera colonies to a specific predatory stimulus and investigated whether and how the same colony may utilize the whole spectrum between 'docility' and 'aggressiveness', ranging from full retreat into the nest to the release of flying, non-guard bee defenders. We used three methodological approaches: First, we simulated natural vertebrate perils applying three regimes of threatening stimuli: (a) shocking the colonies mechanically, (b) exposing them to alarm pheromones, and (c) combining mechanical and pheromonal stimulation. Second, we investigated the role of intrinsic and extrinsic factors on defensiveness and measured the foraging level, ambient temperature and time of day. Third, we selected wide genetic variety in A. mellifera and used test colonies of three African and European subspecies (A. m. scutellata, A. m. capensis, A. m. carnica) which had the similar colony size and which had been pre-selected by manual inspection as 'docile' and 'aggressive'.

\section{Materials and Methods}

\section{Test Colonies}

We conducted experiments with three colonies of A.m. scutellata (scut $_{A-C} ; n=82$ experiments) and A.m. capensis $\left(\operatorname{cap}_{A-C} ; n=52\right)$, and five A.m. carnica $\left(\right.$ carn $_{A-E} ; n=$ 68). Each colony was selected as reportedly 'aggressive', 'intermediate' or 'docile' and consisted of about 10.000 bees. The colonies from Ixopo, Kwa-Zulu-Natal (South Africa) were morphometrically (Hepburn and Crewe 1991) of scutellata origin, those from Grahamstown (South Africa) of capensis origin, the carnica colonies were reared at the beekeepers school in Graz (Austria). The experiments with the African subspecies were carried out in late spring in Grahamstown, South Africa through 2 weeks under diverse weather conditions with ambient temperatures ranging from $12^{\circ} \mathrm{C}$ to $35^{\circ} \mathrm{C}$, from windy to windless. Experiments with the European subspecies were conducted in Graz, Austria during 2 weeks in summer with constant warm weather.

\section{Stimulation Regimes}

We used three ways to disturb the colonies under test. (1) Under the m-regime (Fig. 1), mechanical shocks were delivered to the bees by dropping $200 \mathrm{~g}$ weights through a $50 \mathrm{~cm}$ tube mounted on the top of the hive to transmit the impulse directly onto a plate covering the top-bars of the frames at a rate of one per $2 \mathrm{~s}$ for $3 \mathrm{~min}$. (2) Under the p-regime, the colonies were exposed to alarm pheromones on cotton buds doped with ten stings placed $10 \mathrm{~cm}$ in front of the hive, so that the bees had to fly to reach it. The use of ten stings compensated for the fact that individual honeybees provide different levels of sting pheromone. For each experiment, the sting preparation was made freshly from forager bees, and as the sting pheromones are extremely volatile, we checked the effectiveness of pheromonal stimulation by the smell of the cotton buds, which had at the end of the 3 min of exposition the same strong smell as at the start. Lastly (3), we combined mechanical shocks and alarm pheromones under the mp-regime. 


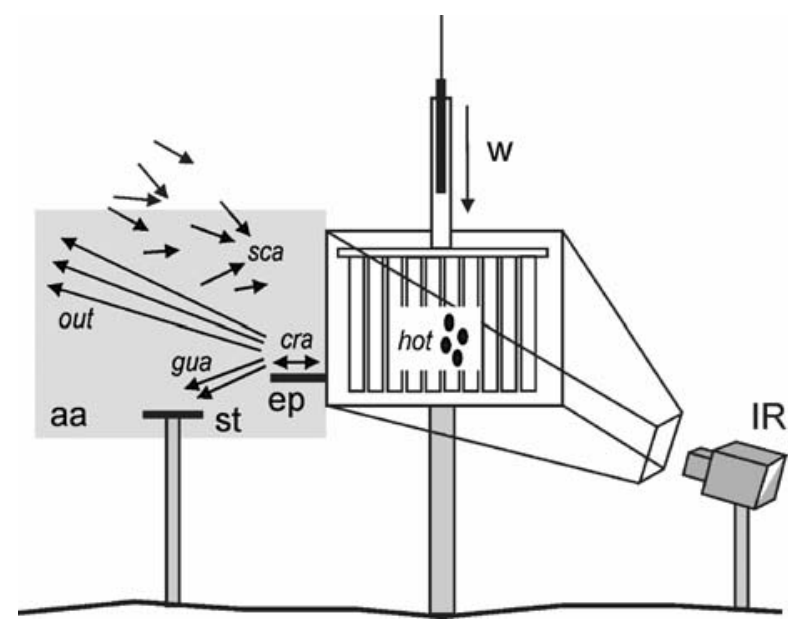

Fig. 1 Experimental setup with a ten-frame Apis mellifera hive. The experiments with the colonies of the three subspecies were conducted with this hive. $w$, tube for delivering mechanical shocks by falling weights; st, preparation of ten stings in front of the hive. Five classes of worker bees had been assessed: $s c a$, bees scanning in front of the hive entrance heading to the hive entrance; out, bees departing from the hive entrance; cra, bees crawling around or staying motionless on the entrance plate; gua, guard bees which flew to the stinger preparation; hot, bees with heated thoraces on the nest surface of the nest inside the hive, recorded by infrared camera $(I R)$. Gray area in front of the hive entrance gives the zone which was recorded by video.

Each experiment comprised three phases: (a) the pre-stimulation (preSTIM) phase in which foraging was measured for $3 \mathrm{~min}$; (b) the stimulation (STIM) phase of $3 \mathrm{~min}$; (c) the post-stimulation (postSTIM) phase of $10 \mathrm{~min}$. The first $2 \mathrm{~min}$ of the STIM- and postSTIM-phases were subdivided into four $30 \mathrm{~s}$ intervals $\left(\mathrm{STIM}_{1}-\right.$ $\mathrm{STIM}_{4}$, and postSTIM 1 - postSTIM 4 respectively). The phases $\mathrm{STIM}_{1}$ and $\mathrm{STIM}_{4}$ were used for the quantification of the 'immediate' response after the onset of the stimulus. Colonies were tested up to 10 days at different weather conditions and ambient temperatures at day times between 9 and $17 \mathrm{~h}$. After each experiment, the colonies remained untouched for at least $1 \mathrm{~h}$.

\section{Behaviour Categories}

Throughout the experiments we video-recorded the assessment zone in front of the hive entrance (Fig. 1) and observed four groups of bees with different locomotor behaviours represented by 'crawlers', 'entrance guards', 'scanners', and 'outflyers'. In Fig. 2, we exemplified this in detail for the p-, $\mathrm{m}$ - and mp-regimes in five selected experiments of two colonies $\left(\mathrm{scut}_{A C}\right)$ in which the rates of the activities of flight and ground traffic were counted in $30 \mathrm{~s}$ intervals. Crawlers represent ground traffic at the hive entrance. The largest sub-group of crawlers were classified as entrance guards (Moore et al. 1987; Breed et al. 2004; Stabentheiner et al. 2002), in particular those, which flew to the stinger preparation in front of the entrance hole under the p- and mp-regimes. Scanners were identified as bees facing the hive entrance in straight or hovering flight. Outflyers were identified as bees heading off the hive in straight flight and were counted continuously in $30 \mathrm{~s}$ intervals. 


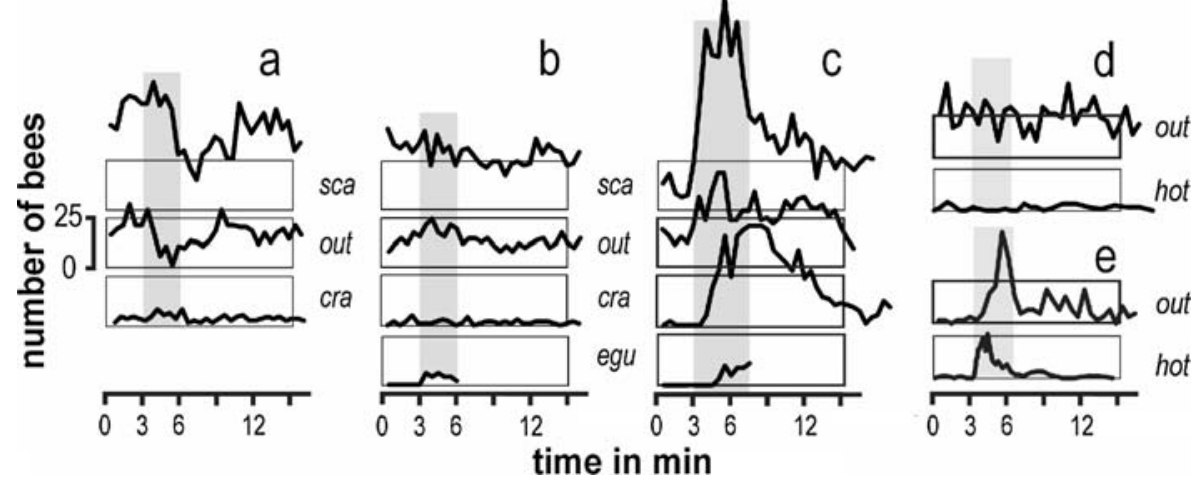

Fig. 2 Principles of ground and flight traffic and of nest arousal in Apis mellifera colonies, under experimental arousal by the m-, p- and mp-stimulation. Simultaneous counts of scanners (sca), outflyers (out), crawlers (cra), entrance guards (egu) and worker bees on the surface of the nest inside the hive with heated thoraces (hot), visualized by infrared imaging. Ordinates: number of flying bees per $30 \mathrm{~s}$ (regarding $s c a$ and $o u t$ ), respectively the number of worker bees at the time of observation (regarding cra, egu and hot); the open squares in the background scale the ordinates ( 0 and 25 counts) and the abscissae ( 0 and 15 min of experimental time); the grey background areas represent the stimulation phase (STIM-phase) between 3 and 6 min of experimental time. (a) colony $s_{c u t}$, m-regime, start of experiment: $2000-10-21$ at $12.56 \mathrm{~h}$; (b) colony $s c u t_{C}$, p-regime, 2000-10-28 at $11.16 \mathrm{~h}$; (c) colony $s c u t_{A}$, mp-regime, 2000-10-28 at $14.29 \mathrm{~h}$; (d) colony $s c u t_{A}$, p-regime, 2000-10-28 at $11.16 \mathrm{~h}$; (e) colony scut $t_{A}$, mp-regime, 2000-10-24 at $11.27 \mathrm{~h}$.

Additionally, we measured the arousal conditions of the test colonies, by imaging the temperature patterns on the surface of the nest inside the hive (Fig. 1). For that, we used a Thermacam SC2000 Infrared camera (FLIR, Inc), which was calibrated by a reference source of known temperature and emissivity (Stabentheiner and Schmaranzer 1987). The camera viewed directly onto the frames from the side without any barrier in between. Camera and beehive were covered by a black curtain that also closed the hive for the bees. Arousal of the nest by stimulation in the m-, p-, and mp-regime is quantified by the number of 'hot' bees which heated up their thoraces over $40^{\circ} \mathrm{C}$. In this paper, we illustrate such arousal effects during the experiments only exemplified for the colonies $s c u t_{A}$ (Fig. 2d,e) and $s c u t_{C}$ (see chapter "Results").

\section{Data Analysis}

The outflyer rate (OUT) is the main parameter of this analysis; it provides an appropriate measure of two behavioural features of honeybee colonies, of their foraging level and their defensiveness. It was measured in $30 \mathrm{~s}$ intervals ( $i=1$ to 32 ) in the 16 min of experiments. The outflyer rate under undisturbed conditions (which were given in the pre-stimulation phase) quantifies the foraging activity of the colony for the time of experiment. The mean outflyer rate in the pre-stimulation phase $m \mathrm{OUT}_{\text {prestim }}=\sum$ OUT $[i] / 6$; with $i_{-}=1$ to 6 as the number of 30 s-intervals) was used as a reference to assess the net outflyer rate (netOUT [i]=OUT [i]$\left.m \mathrm{OUT}_{\text {prestim}}\right)$, which is scaled in the paper by the number of bees per minute. The parameter net outflyer rate focuses on the responsiveness of the colony to the stimulation in the following aspects: Zero values of the net outflyer rate in the 
STIM- and postSTIM phases display a non-responding, non-aroused state of the test colony. Changes of outflyer rate in context with stimulation refer to colony defensiveness. Positive values denote responses, which raise the outflyer rate over the initial foraging level. An increasing outflyer rate after the onset of stimulation signifies the release of flying defenders and is in this paper, therefore, termed as "releasing response". To the opposite, decreasing outflyer rates in context of stimulation signal down-regulation of outside-hive activities of the colony. This colony response may even reduce the outflyer activity below its initial foraging level, which causes negative values of the net outflyer rates. Such colony reaction with outflyer rates decreasing after the onset of stimulation is termed as "retreating response". The colony recovers to its normal foraging activity if the low outflyer rate after a stimulus-induced retreat has again increased.

\section{Statistics}

Parametric ( $t$ test) or nonparametric (Chi-square test, Wilcoxon Signed Rank Test) tests were used to compare. Gaussian and non-Gaussian distributed data sequences in order to trace differences in behaviors between two experimental states, such as before and after the onset of shimmering. Correlations were characterized by the regressions of the original data values of the respective behavioral classes, or facultatively (see below) of their arithmetic means. The regressions were fitted by optimizing their coefficients of determination $\left(R^{2}\right)$ and tested for significance by Spearman rank order correlation test. Inter-group (e.g. between m-releaser and $\mathrm{m}$ retreater colonies) and intra-group (e.g. among m-releaser and m-retreater colonies) differences of outflyer rates were tested using the One Way ANOVA (Sigmastat). This concerned the foraging rates in the preSTIM phase and the 'immediate' responses after the onset of stimulation in the $\mathrm{STIM}_{1}$ and $\mathrm{STIM}_{2}$ intervals.

\section{Results}

Identifying the Goals of Bees in Ground and Flight Traffic in Front of the Hive

Foragers Flight traffic under undisturbed conditions referred mainly to foragerswith the exception of the facultative midday display, when young bees perform their first orientation flights (colonies had not been tested during this midday display). Also under stimulation, flight traffic may predominantly regard foraging matters. This is exemplified in Fig. 2a, when the test colony scut ${ }_{C}$ displayed 50 scanner bees per $30 \mathrm{~s}$ in front of the entrance hole at the start of m-stimulation. The scanner rate is likely to be overestimated because one and the same scanner bee may enter the assessment zone in front of the hive several times before it finally lands near the hive entrance. Nevertheless, the time course of the scanner rates lagged by 3 min behind that of the outflyer group (Fig. 2a). The test colony scut ${ }_{C}$ was of the retreater type and decreased its scanner and outflyer rates during m-stimulation. Scanners and outflyers waxed and waned in a similar time course, but the scanner curve was delayed. Such a phase lag between outflyers and scanners of 3 min indicates that one and the same individuals had been scored twice in succession, first, when departing 
from the hive as outflyers, and second, 3 min later on their return as scanners. This is unequivocal evidence that in a retreater-type colony outflyers and scanners are predominantly foragers.

Entrance guards The definition of entrance guards (Stabentheiner et al 2002, 2007; Breed et al, 2004) regards bees at the entrance site of bee nests which inspect the incoming traffic. In our paper it are the crawlers ( $\mathrm{cra}$ ) which represent this group. Undisturbed, the colony holds the number of the bees at the hive entrance constant. If the colony is stimulated externally under the p-regime, some of the entrance guard (egu in Fig. 2b) happened to fly to the sting preparation. The exposure to alarm pheromones alone did not provoke any change in the rate of scanners and outflyers (sca, out in Fig. 2b), and did not arouse the colony at the nest itself; the number of bees with heated-up thoraces (hot in Fig. 2d) remained low and constant. The pattern of the rate of outflyers and scanners in this example (Fig. 2b) fits to this observation of a non-arousal state, and the time-lagged pattern of their rates identifies them also as foragers.

Soldier bees Under massive arousal of the nest, as it is true for the mp-regime (Fig. 2c), all behaviour classes of worker bees in front of the hive increased in numbers. As the first reaction, the number of nest bees with heated thoraces increased (hot in Fig. 2e), which is an expression for recruitment of soldier bees, followed by the outflyers and scanners (out, sca in Fig. 2c) and by the crawlers (cra in Fig. 2c) and those part of the entrance guards (egu in Fig. 2c), which flew to the sting preparation. As an 'immediate' response to stimulation, outflyer and scanner rates peaked here not in a time-lagged way but synchronously (Fig. 2c). The selected example documents the release of highly 'aggressive' bees, which had pursued the experimenter when operating near the hive. Thus, such cohorts of scanners, outflyers and crawlers were clearly engaged in a defensive mission. They were of heterogeneous origin, and combined foragers, entrance guards as well as soldier bees (Breed et al 2004), which had been mobilised directly from the nest. All of them may have taken flight off to the harasser.

The quota of foragers and soldier bees can be estimated by the count of the outflyers and of those bees inside the hive which have heated up their thoraces to more than $40^{\circ} \mathrm{C}$. The forager part of the outflyer rate can be assessed under the undisturbed conditions, e.g. in the pre-stimulation (preSTIM) phase of the experiment, the contingent of soldier bees can be estimated by infrared monitoring of the nest interior, but it also represented by the increasing part of net outflyer rates. We gained corroborative evidence (compare Fig. 2d,e) that in releaser-type colonies the 'immediate' responses to $\mathrm{m}$ - or $\mathrm{mp}$-stimulation originate from the internal mobilisation of the colony. Therefore it is plausible to propose that the mobilisation of soldier bees (cf. Breed et al. 1992) causes the increase of the net outflyer rate after the onset of $\mathrm{m}$ - or mp-stimulation. A strong support for this surmise is given by the fact that in the course of mp-stimulation the number of nest bees which heated up their thoraces strongly graded along a linear correlation (e.g. for scut $_{C} ; r=0.908$; $P<0.01$; Linear regression test, Sigmastat; Kastberger and Stabentheiner, in preparation) with the number of outflyers (compare Fig. 2d,e) if the outflyer rate was assessed with a time lag of $100 \mathrm{~s}$. We categorized these cohorts which caused 
the stimulus-driven peaks in the outflyer curves more neutrally as 'flying defenders', in particular because it was not possible to specify in the bulks of bees, which definitively pursued the experimenter during mp-experiments, the proportion between entrance guards and freshly recruited soldier bees.

\section{Colony Responsiveness to Mechanical and Pheromone Stimulation}

The responses of the test colonies to mechanical stimuli ranged from the release of flying defenders to the retreat to the nest (Fig. 3, m-graphs). Some of the colonies $\left(\operatorname{cap}_{A}, s \mathrm{cut}_{A-B}, \operatorname{carn}_{A}\right)$ were more 'aggressive' and mobilized flying guards within $15 \mathrm{~s}$. Other colonies $\left(\mathrm{cap}_{B-C}, s c u t_{C}, \operatorname{carn}_{B-C}\right)$ were more 'docile' and reduced their net outflyer activity during and after stimulation. Both strategies, 'aggressive' and 'docile', differed in strength and in a colony-specific way. For example, the colonies $\operatorname{cap}_{B-C}$, and $\operatorname{carn}_{B}$ increased the outflyer rate after the onset of stimulation for a short time, other colonies, such as $s c u t_{A-B}$, or $c a r n_{A}$ increased it strongly. After the obvious release of flying guards most colonies decreased their net outflyer activity and retained their initial outflyer rate (e.g. in $\operatorname{cap}_{A}$ ) or went even below their initial foraging rate (such as in $s c u t_{C}, \operatorname{carn}_{B-C}$ ) showing retreatment.

The exposure to alarm pheromone alone hardly affected the outflyer rate and accounted for only slight retreats in the initial post-stimulation phase (Fig. 3, p-graphs). However, combining mechanical shock and alarm pheromone as it is done in the mpregime evoked colony responses, that differed from those observed in the m-regime in three aspects (Fig. 3, mp-graphs): 'Aggressive' colonies (such as $\operatorname{cap}_{A}, \mathrm{scut}_{A-B}, \mathrm{carn}_{A}$ ) responded with massive and instantaneous release of flying defenders. 'Docile' colonies (such as $\operatorname{cap}_{C}, s_{c} t_{C}, \operatorname{carn}_{B-C}$ ) released flying defenders during stimulation but reduced the flights in the post-stimulation phase. Only the test colony $\operatorname{cap}_{B}$ did not release flying defenders and retreated during mp-stimulation in an enhanced way.

Summarizing, the variety of defence types in honeybee colonies, if tested under multimodal conditions reaches from 'docile' to 'aggressive' even if different subspecies are considered. In the next chapters we typify in more details the test colonies, which had been preselected regarding their defensiveness by gross manual inspection in the routine of beekeepers. For that, we applied methods which should be manageable in the field to establish controlled arousal conditions and to assess behavioural criteria such as the net outflyer rate and the foraging rate which allow for a quantification of colony defensiveness.

\section{Defence Typology Under the m-Regime}

The responsiveness of colonies to stimuli was traced by the net outflyer rates after the onset of m-stimulation (regarding the stimulation phases $\mathrm{STIM}_{1}-\mathrm{STIM}_{4}$ ) and

Fig. 3 Reactivity patterns of the nine (of 11) test colonies of three Apis mellifera subspecies (A.m. capensis: cap $_{A-C}$; A.m.scutellata: $s c u t_{A-C} ;$ A.m.carnica: carn $\left._{A-C}\right)$. The colonies were investigated under three stimulation regimes ( $m, p, m p)$. Grey areas mark the 3-min stimulation period (STIM-phase). Ordinate, the net outflyer rates (lines with vertical bars: means $\pm \mathrm{SE}$ ) of the colonies under the respective stimulus regimes; horizontal thin lines across the fields mark the zero level, which is equivalent to the arithmetical means of the outflyer rates in the $3 \mathrm{~min}$ of the pre-stimulation (preSTIM) phase. After stimulation, the colonies had been observed for further $10 \mathrm{~min}$ in the post-stimulation (postSTIM) phase. 


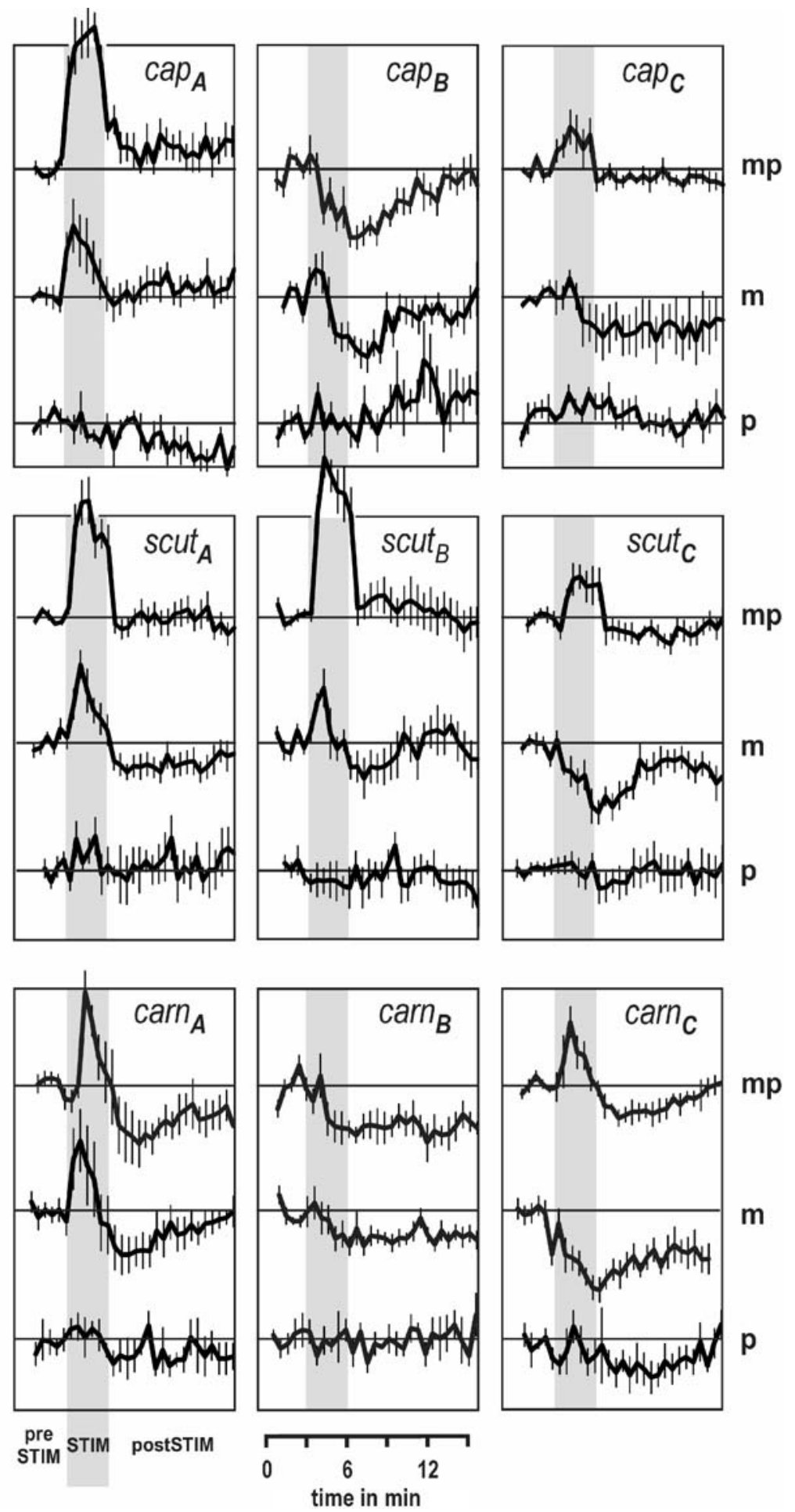


after the termination of m-stimulation (regarding the poststimulation phases postSTIM 1 - postSTIM 4 ). We sorted the test colonies from colony 1 to colony 11 (for coding the colonies, see legend of Fig. 4) with respect of a decreasing strength of the 'immediate' defence response (Fig. 4a). Surprisingly, the colonies, resolved into two defence types (Fig. 4a), irrespective of the membership of the subspecies. The colonies 1-5 released, as the 'immediate' response, flying defenders and were, therefore termed 'm-releasers'. The colonies 6-11 kept the outflyer rate at constant level or reduced it, which corresponded to the retreatment response. These colonies were termed 'm-retreaters'.

This dual categorization of the 11 test colonies by m-releasers and m-retreaters (Fig. 4a) becomes even more obvious if the 'immediate' defence responses of the colonies under m-stimulation were related to the momentary colony-specific foraging levels under undisturbed conditions, that were previous to stimulation. Colony defensiveness can then be quantified by the respective regression functions which are diversified significantly for the m-releaser and m-retreater groups (Fig. 4b). Additionally, the ANOVA tests (Fig. 4c) proved here significant intercolony and inter-group differences among and between m-releasers and $\mathrm{m}$ retreaters, regarding foraging levels under undisturbed conditions in the preSTIM phase and regarding the 'immediate' responses to m-stimulation (in terms of the net outflyer rates in the $\mathrm{STIM}_{1}$ and $\mathrm{STIM}_{2}$ phases).

Overall, the m-regime data demonstrated, that all 11 test colonies responded by increasing their net outflyer rates in the first phases of stimulation when the mean foraging levels of the colonies, measured over the experimental session, decreased (Fig. 4). This principle, that the foraging activity modulates colony defensiveness, is obviously fundamental for Apis mellifera colonies, it was also assessed in individual colonies $(P<0.01$; Spearman test; data not shown explicitly in graphs) under the $\mathrm{m}$ regime when the environmental conditions have changed (e.g. regarding ambient temperature or the time of day).

\section{Constancy of Defence Typology}

The experiments have been performed with each of the test colonies on three sequential days at different day times and varying ambient temperatures (see "Materials and Methods"). The colonies were considerably influenced by environmental factors, and therefore, respective variation of the responses to normative stimuli had been expected. The question was whether honeybee colonies would alter their response type, in particular, whether they would shift under changing environmental conditions from the m-releaser to the m-retreater state or vice versa. To prove this, we measured the 'immediate' colony responses under the m-regime and catalogued the state of defensiveness of the test colonies throughout the experimental session.

Although the environmental conditions altered extraordinarily, regarding ambient temperature, in particular (see "Materials and Methods"), the response patterns of the 11 test colonies to m-stimulation varied only moderately (Fig. 5). Colonies 1-5 maintained their 'aggressive' character to release flying defenders $(P<0.05 ; z$-test $)$, and the colonies $8-11$ continued to retreat to the nest throughout the session $(P<$ 0.05 ; $z$-test); only the colonies 6 and 7 switched from releasing to retreating mode. 
a

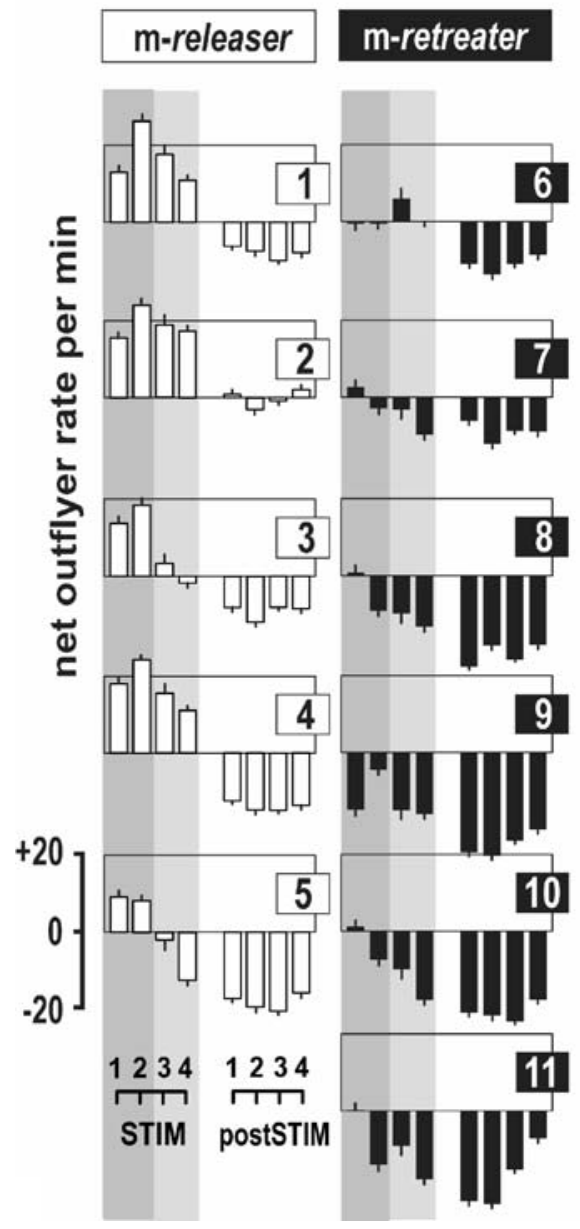

b

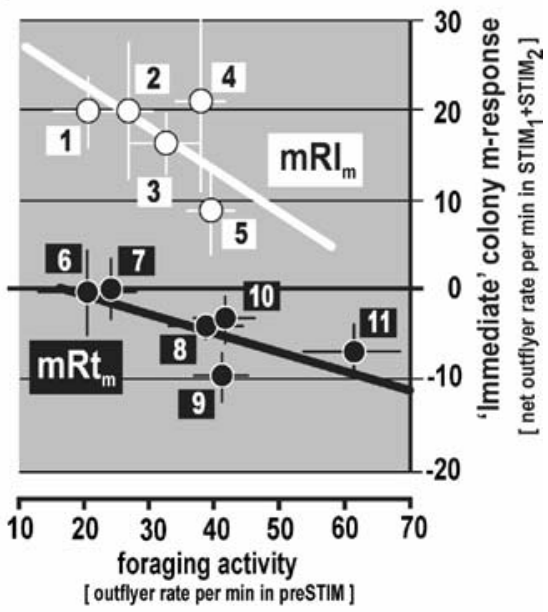

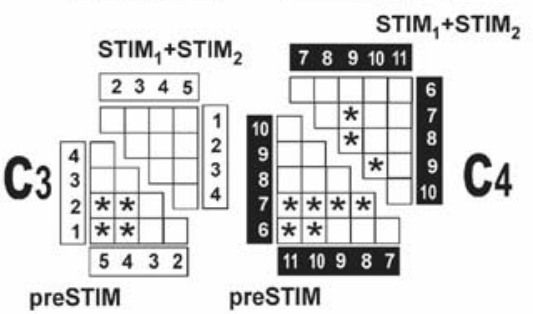

Fig. 4 Categorizing colony defence types in three subspecies of Apis mellifera under mechanical stimulation (m-regime). a The responses of the test colonies (columns and vertical bars, means $\pm \mathrm{SE}$ ) assessed by the net outflyer rates in the four stimulation phases $\left(\mathrm{STIM}_{1}-\mathrm{STIM}_{4}\right.$; marked by grey background $)$ and in the four poststimulation phases (postSTIM -postSTIM $_{4}$; on white background). The test colonies (codes: 1, scut $A_{A} ; 2$, cap $_{A}$; 3, scut $_{B} ; 4, \operatorname{carn}_{A} ; 5, \operatorname{cap}_{B} ; 6, \operatorname{cap}_{C} ; 7, \operatorname{carn}_{C} ; 8, \operatorname{carn}_{D} ; 9, \operatorname{carn}_{B} ; 10$, scut $_{C} ; 11$, carn $_{E}$ ) were sorted regarding decreasing values of the "immediate" response (defined as the net outflyer rates in the $\mathrm{STIM}_{1}$ and STIM $_{2}$ phases); the colonies 1-5 (open symbols) increased the outflyer rate after stimulation and are thus termed as 'm-releaser' colonies, whereas the colonies 6-11 (closed symbols) were neutral or decreased the outflyer rate after stimulation and were termed as 'm-retreater' colonies. b Plots of the behaviours of the colonies as coded under a (circles and bars; means $\pm \mathrm{SE})$; ordinate, the 'immediate' responses $\left(y_{\mathrm{m}}={ }_{\text {net }} \mathrm{OUT}_{\mathrm{STIM} 1+\mathrm{STIM} 2}\right.$ as the mean net outflyer rates in $\left.\mathrm{STIM}_{1}+\mathrm{STIM}_{2}\right)$ to mechanical stimulation; abscissa, the foraging activity $\left(x_{\mathrm{m}}=\right.$ OUT $_{\text {prestim }}$ as the outflyer rate in the pre-stimulation phase, which corresponds to the forager rate under undisturbed conditions); regression polynomials of the means of m-releaser $\left(m \mathrm{Rl}_{\mathrm{m}}\right)$ colonies, $y_{\mathrm{m}}=32.090$ $0.472 \times x_{\mathrm{m}}$ (with $r=-0.415 ; N=5$ colonies; $P<0.01$, Spearman Test; based on 38 experiments) and of $\mathrm{m}-$ retreater $\left(m \mathrm{Rt}_{\mathrm{m}}\right)$ colonies: $y_{\mathrm{m}}=3.584-0,212 \times x_{\mathrm{m}}$ (with $r=-0.474 ; n=6$ colonies; $P<0.01$; based on 40 experiments). c Plots summarizing the results of the ANOVA tests; stars give the significance levels $(P<0.05)$ of intercolonial differences of outflyer rates: the differences between m-releaser (1-5) and m-retreater (6-11) colonies concerning the foraging rates in the preSTIM phase $\left(c_{1}\right)$ and the 'immediate' m-responses $\left(c_{2}\right)$, and the differences of the foraging rates (preSTIM) and 'immediate' responses $\left(\mathrm{STIM}_{1}+\mathrm{STIM}_{2}\right)$ among $\mathrm{m}$ releaser colonies $\left(c_{3}\right)$ and among m-retreater colonies $\left(c_{4}\right)$. 
Fig. 5 The aspect of constancy of the colony defense type in Apis mellifera under the m-regime. Codes of the 11 test colonies, see Fig. 4; colonies $1-5$ are of the releaser type, colonies 6-11 are of the retreater type. Ordinate, the 'immediate' responses to $\mathrm{m}$-stimulation; abscissa, number of experiments which were conducted at different times of day and ambient temperatures in the course of three consecutive days. Signs in brackets give the main $(P<0.05, z$-test $)$ direction of 'immediate' responses, corresponding to releaser-type (plus sign), retreater-type (minus sign), or switching from releaser to retreater-type (plus-minus sign). The experimental conditions (regarding number of experiment, times of day and ambient temperature) obviously are irrelevant for the signs of the 'immediate' responses in subsequent experiments.

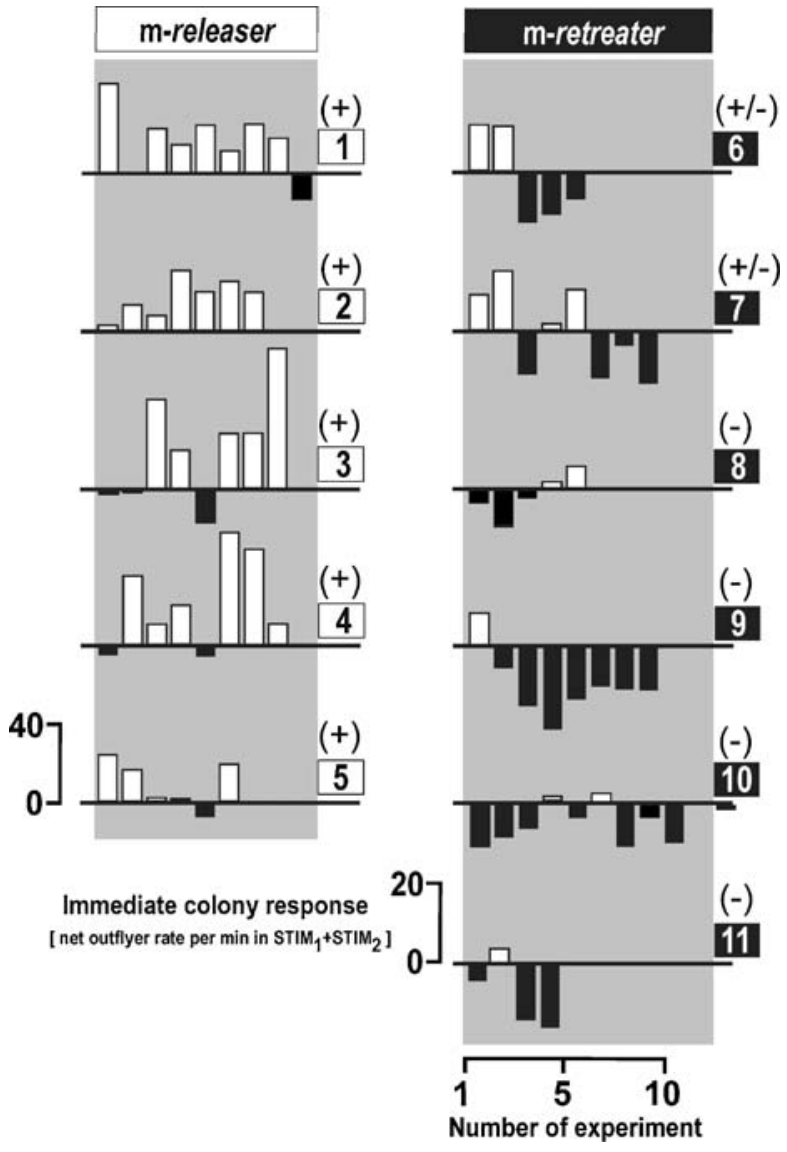

In a more general view, the test colonies maintained their response type under the mregime at least for the sequence of three experimental days.

Defence Typology Under the mp-Regime

The survey in Fig. 3 illustrates that mere p-stimulation would not bring any colony respond to release flying defenders or by a retreatment activity (Figs. 2 and 3). It also demonstrates that the responsiveness to the stimuli was massively enhanced in strength, and the spectrum of defence typology became more diverse, if the $\mathrm{m}$ - and p-regimes were combined. The question was in which way this combined stimulation would modify that typology, which had previously been defined for the m-regime.

For that, we tested nine colonies (with the exception of the colonies $\operatorname{carn}_{D E}$ ) under the mp-regime. The criterion for sorting the colonies 1-9 in Fig. 6a was the same as in Fig. 4a and referred to the decrease in strength of the "immediate" responses in the m-regime. The mp-responses of the colonies in the $\mathrm{STIM}_{1}-\mathrm{STIM}_{4}$ and in the postSTIM -postSTIM $_{4}$ phases were displayed in Fig. 6a, and, similarly to Fig. 4b, their'immediate'mp-responses were plotted in Fig. $6 \mathrm{~b}$ against the foraging 
a

\section{m-releaser m-retreater}

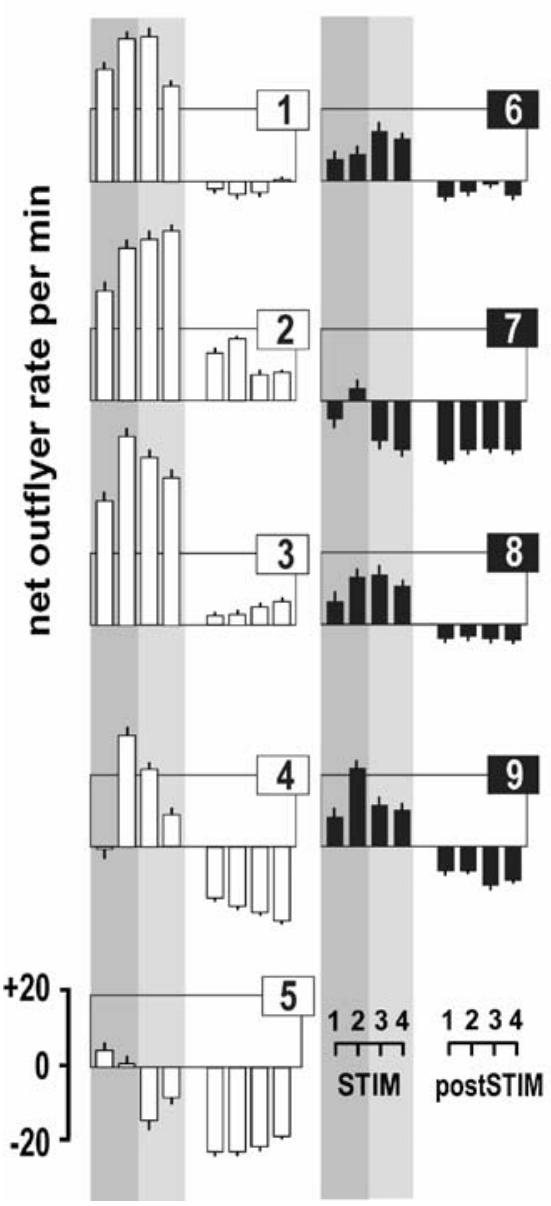

b

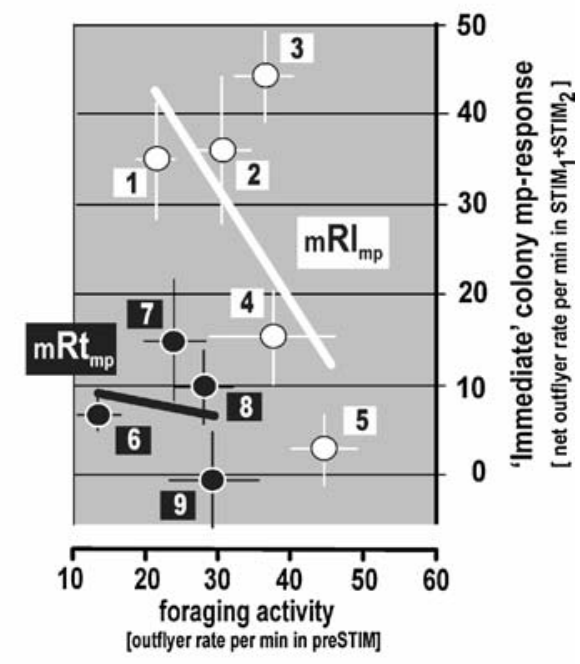

presTIM
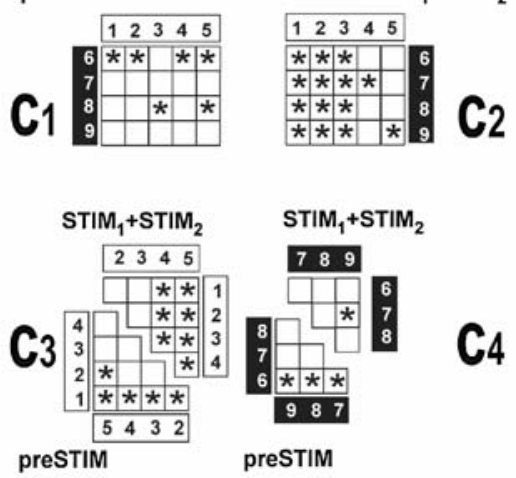

Fig. 6 Categorizing the colony defence types in Apis mellifera in experiments under combined stimulation (mp-regime) but using the same classification as under the m-regime (m-releaser, m-retreater). a The mp-responses (columns and vertical bars, means $\pm \mathrm{SE}$ ) of the test colonies of the net outflyer rates during stimulation $\left(\mathrm{STIM}_{1}-\mathrm{STIM}_{4}\right)$ and afterwards (postSTIM 1 -postSTIM $)_{4}$. The colonies 1-5 (open symbols, m-releaser type colonies) and the colonies 6-9 (closed symbols, m-retreater type colonies) were sorted regarding decreasing values of the 'immediate' m-responses (see Fig. 5); note, the colonies 10,11 were not investigated in the mp-regime (for coding 1-9, see Figs. 4, 5). b Plots of the behaviours of individual colonies (circles \pm bars, means $\pm \mathrm{SE}$ ): Ordinate, the 'immediate' mp-responses (mean net outflyer rates in $\left.\mathrm{STIM}_{1}+\mathrm{STIM}_{2}, y_{\mathrm{m}}={ }_{\text {net }} \mathrm{OUT}_{\mathrm{STIM} 1+\mathrm{STIM} 2}\right)$ to mp-stimulation; abscissa, the foraging activity (defined by the outflyer ( $=$ forager) rate in the prestimulation phase, $x_{\mathrm{mp}}=\mathrm{OUT}_{\text {prestim}}$ ); regression polynomials of the means of m-releaser type colonies tested in the mp-regime (line plot $\left.\mathrm{mR} 1_{\mathrm{mp}}\right): y_{\mathrm{mp}}=$ $71.06-1.30 \times x_{\mathrm{mp}}$ (with $r=-0,651 ; N=5$ colonies; $P=0,23$, Spearman Test, Sigmastat; based on 47 experiments) and of m-retreater type colonies tested in the mp-regime (line plot $\mathrm{mRt}_{\mathrm{mp}}$ ): $y_{\mathrm{mp}}=11.627-$ $0.1656 \times x_{\mathrm{mp}}$ (with $r=-0.180 ; N=4$ colonies; $P=0,82$; based on 28 experiments). c Plots summarizing the results of the ANOVA tests; stars give the significance levels $(P<0.05)$ of intercolonial differences of outflyer rates: the differences between m-releaser (1-5) and m-retreater colonies $(6-9)$ concerning $\left(c_{1}\right)$ the foraging rates in the preSTIM phase and $\left(c_{2}\right)$ the 'immediate' $\left(\mathrm{STIM}_{1}+\mathrm{STIM}_{2}\right)$ mp-responses, and the differences of the foraging rates (preSTIM) and 'immediate' mp-responses $\left(\mathrm{STIM}_{1}+\mathrm{STIM}_{2}\right)$ among $\mathrm{m}$ releaser type colonies $\left(c_{3}\right)$ and m-retreater type colonies $\left(c_{4}\right)$. 
levels. Finally, the foraging status and the'immediate' mp-responses of the colonies have been tested (Fig. 6c; cf. Fig. 4c) for differences between and among the mpreleaser and mp-retreater groups.

The data distribution of Fig. $6 \mathrm{~b}$ seems to be more complex than under the mregime (Fig. 4b), and there are, at least, two ways to explain the findings. The first view accepts the same group criteria as under the m-regime (Figs. 4 and 5) and postulates that the colonies 1-5 had boosted their defensiveness under the mpregime to release more flying defenders (Fig. 6c). Similarly to the m-regime, this defensiveness under mp-stimulation depends on the foraging level under undisturbed conditions with the consequence that, if a colony had a higher foraging activity, less numbers of flying defenders were released. The regression functions $\left(\mathrm{mRl}_{\mathrm{mp}}, \mathrm{mRt}_{\mathrm{mp}}\right.$ in Fig. 6b) symbolize this homology to the findings of the m-regime (Fig. 4b). The only weakness of this conception is that it cannot be statistically proved by the given data base.

The second view to explain the data distribution of Fig. $6 \mathrm{~b}$ is, however, soundly proved by ANOVA tests (Fig. 6c). It categorizes the mp-data of the nine colonies in contrast to that of the m-regime into two groups. The colonies 1-3 differed in their 'immediate' mp-responses from all other test colonies by having massively released flying defenders and by not having retreated in the post-stimulation phase (Fig. 6a). In this concept, these three colonies are therefore termed as 'strong mp-releasers'. The other six colonies, the former m-releaser colonies 4 and 5, and the former $\mathrm{m}$ retreater colonies 6-9, released much lower quantities of flying defenders during mp-stimulation and retreated in the poststimulation phase (Fig. 6a); therefore they are here termed as 'weak mp-releasers'.

\section{Modulation of Defence Typology by Foraging Status}

If analysed colony-wise, the data of the mp-regime allow proposing a third aspect of how the defensiveness of honeybee colonies can be instigated or calmed down. Fig. 7 exemplifies this approach for three selected colonies. First, the colony $s \mathrm{cut}_{C}$, which belonged to the category 'strong mp-releaser' (see Fig. 6b), not only released a large bunch of flying defenders during mp-stimulation, it also showed a positive correlation between the 'immediate' responses to mp-stimulation and foraging (Fig. 7a,b). With other words, colonies of such defence type would turn the more 'aggressive' the more their foraging traffic increased, and represent here the 'superaggressive' position in the bulk of our test colonies. Such a principle of positive grading of foraging status and releasing defenders is found for the mp-regime, but not for the m-regime.

The colonies $c a p_{B}$ (Fig. 7c,d) and $c a p_{C}$ (Fig. 7e,f) are members of the category 'weak mp-releasers'. Both colonies have in common that they showed a negative correlation between the release of flying defenders and the foraging activity. However, while colony $\operatorname{cap}_{C}$ released quite a lot of flying defenders under low foraging activity and reduced this release under high foraging level (Fig. 7b), colony $\operatorname{cap}_{B}$ decreased its net outflyer rate during mp-stimulation even below zero and turns under high foraging levels to a mp-retreater (Fig. 7c).

Summarizing, while mono-modal stimulation such as m-regimes allow typify colony defence in Apis mellifera into at least two categories, combined stimulation 


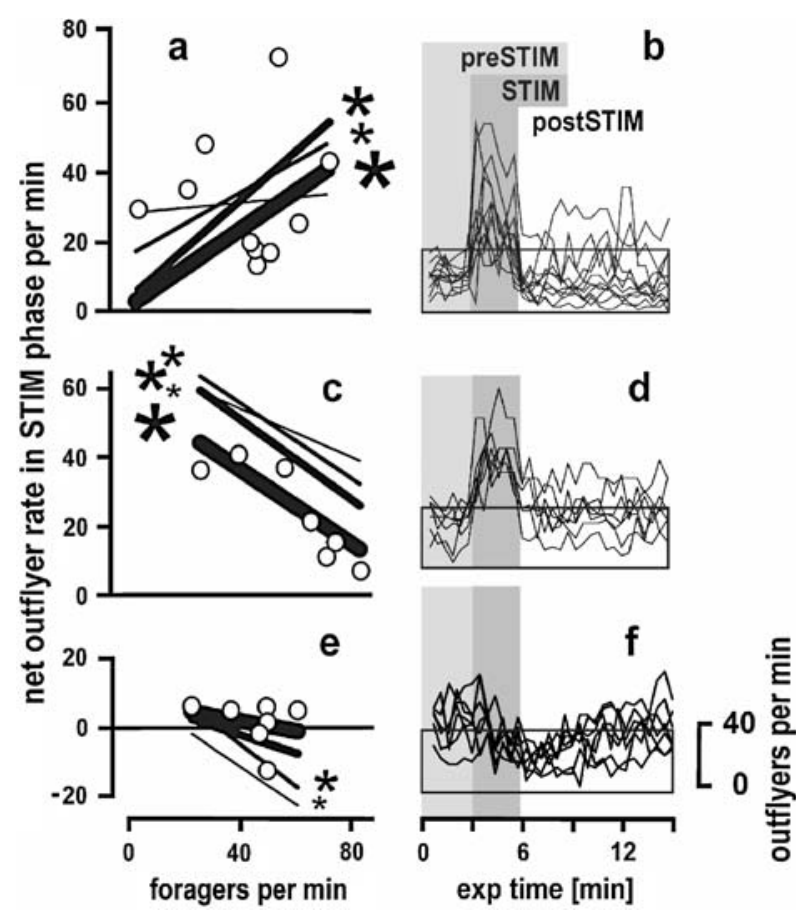

Fig. 7 Foraging state modulates the defence responses exemplified in three selected colonies under the mp-regime. a, b scut $_{C}$; c, d cap $_{C}$; e, f $c a p_{B}$; graphs on the left side, the net outflyer rates during mpstimulation plotted against the foraging activity (outflyer rates in the preSTIM phase); a, c, d regressions refer to responses in the four stimulation phases $\left(\mathrm{STIM}_{1}-\mathrm{STIM}_{4}\right.$ : from thick to thin lines), the stars mark significant correlations $\left(P<0.05\right.$; Spearman test; $\mathrm{STIM}_{1}$ to $\mathrm{STIM}_{4}$ : from big to small stars); the open dots exemplify the data distribution of single experiments and refer only to the $\mathrm{STIM}_{1}$ phase; b, d, f superimposed outflyer curves of all experiments conducted with the given colonies; ordinate, outflyer rates per minute; abszissa, experimental time in minutes; the grey areas give prestimulation (preSTIM) and stimulation (STIM) phases, white background refers to poststimulation (postSTIM) phase.

as represented by the mp-regime would diversify defensiveness into a startling variety of colony-specific traits (see summarization in Fig. 8).

\section{Discussion}

\section{The Retreater-Releaser Concept}

The paradigms 'aggressiveness' and 'docility' are important for apiarists but are still too fuzzy to characterize appropriately the variety in the defensiveness of honeybee colonies. We selected 11 test colonies from three subspecies of Apis mellifera according to an initially subjective and vague assessment of their aggressiveness as low, intermediate and high. Under test in the m-regime, these colonies were roughly split into two classes, 'm-releasers' and 'm-retreaters'. Releaser colonies (Fig. 4a, colonies 1-5) produced flying defenders at a rate of up to more than 20 bees per minute after the onset of m-stimulation, and reduced the outside-hive activities 


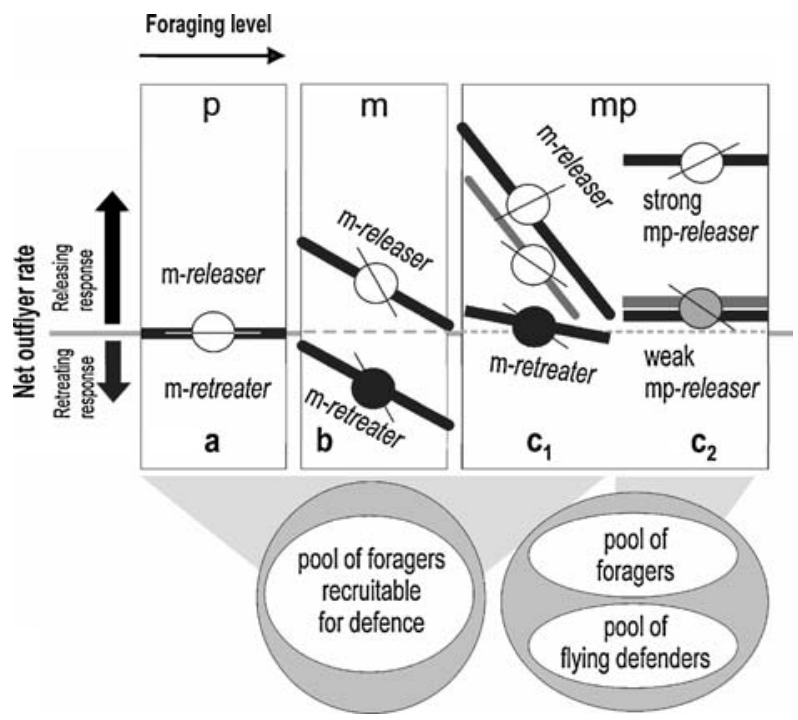

Fig. 8 Summarization of how colony defense of the Western honeybee (Apis mellifera) is affected by three regimes of stimulation ( $m$-, $p$ - and $m p$-) and foraging activity. In these sketches the 'immediate' defense response (ordinate), the net outflyer rates in the $\mathrm{STIM}_{1}$ and $\mathrm{STIM}_{2}$, phases, is plotted against the foraging level (abscissae), defined by the outflyer rate in the preSTIM phase. Correlations between net outflyer rates and foraging levels were symbolized twofold: first regarding the behaviours of individual colonies by the regression sketched by thin cross lines through the circles, and second regarding the data distribution of the colony defence types by the regression sketched by thick black and grey cross lines. Response values above zero level (grey dashed horizontal line) display the release of flying defenders, response values below zero display the retreat to the nest. a p-regime: the exposition to alarm pheromone did not affect the outflyer rate. b Under the m-regime, two defence types of colonies (m-releaser, $\mathrm{m}$ retreater) were distinguished; with increasing foraging level both groups reduced the net outflyer rate, that means that m-releaser colonies reduced the release response, and m-retreater colonies intensified their retreat to the nest. c Under the mp-regime, the response curves which occurred under the m-regime generally shifted upwards, but the former m-releaser colonies are assumed to split into two subgroups: some colonies (weak mp-releasers) reduced the release of flying defenders rate under increasing foraging activity, others (strong mp-releasers) showed the opposite trend (thin cross lines in circles in c). As a consequence, it can be assumed that colonies may organize their worker bees in one (regarding $\mathbf{a}, \mathbf{b}, \mathbf{c}_{\mathbf{1}}$ ) or two (regarding $\mathbf{c}_{2}$ ) pools of which foragers or as flying defenders can be recruited by separate or conjoined principles (see text in "Results" and "Discussion").

below the initial foraging level afterwards. Retreater colonies (Fig. 4a, colonies 611) reduced the net outflyer rate gradually by more than 20 outflyers per min below the foraging rate during stimulation and recovered slowly only minutes afterwards. The fact that the test colonies conformed to type throughout the experimental programme (that is: m-releaser colonies mostly remained 'aggressive', and $\mathrm{m}$ retreater colonies remained 'docile') provides the main support for the surmise that the diversification of colonies into m-releasers and m-retreaters does reflect differences in genetic dispositions rather than being caused by environmental factors.

\section{The Impact of Alarm Pheromones on Defensiveness}

Isopentylacetate (IPA) is considered the most effective components of the honeybee alarm pheromone (Boch and Shearer 1966, 1967; Crewe and Hastings 1976; Crewe 
1977; Whiffler et al. 1988). It is usually taken for field tests to assess the defensiveness of colonies. The most common method is the moving leather ball (Schua 1952; Maschwitz 1963, 1964; Boch and Shearer 1966, 1971; Blum 1969; Crewe 1977; Collins and Rothenbuhler 1978; Collins 1979; Collins et al. 1989), which is presented as a predator dummy in front of the hive and which the bees may attack and sting. Nevertheless, there are variations of this method (Collins and Kubasek 1982; Moritz et al. 1987, Southwick and Moritz 1987; Breed et al. 1990) in which IPA is sprayed into the opened hive, or is combined with mechanical shocks. Generally, the number of stings in the leather ball per unit time is routinely taken as a measure of the aggressiveness of the colony.

In our opinion, there are some weaknesses of the leather ball method that restrict a full explanation of the impact of alarm pheromone on defensiveness. This method joins alarm pheromones with mechanical or visual disturbances of undefined strength (e.g. Collins and Kubasek 1982); it offers experimental concentrations of IPA which are unnaturally high (Moritz et al. 1987, Southwick and Moritz 1987), and causes scent clouds of alarm pheromone which increase with the rising number of stings.

We applied a contrary test procedure by leaving the arrangement of the hive unchanged, and by the use of controlled stimulation under three (m-, p-, mp-) regimes and exposure of the colonies facultative to a definable and natural scent level of alarm pheromone. Thus, we contribute new findings of how alarm pheromones modulate colony defensiveness.

In our experiments, alarm pheromones presented in front of the hive without any mechanical disturbance (Fig. 3, p-graphs) had no visible effect on the undisturbed colony, at least not regarding the outflyer rate nor regarding the number of nest bees with heated thoraces (Fig. 2d,e). Both findings provide evidence that alarm pheromone scent per se is ineffective in alarming or alerting the Western honeybee colony. It brings entrance guards to the external pheromone source, but does not mobilize soldier bees in the nest. This makes sense, as the p-regime used in our investigation was highly experimental. The entrance guards benefit the colony if they value such an artificial stimulus as a non-alarming signal. Remarkably, this colony reaction was essentially the same in all scutellata, capensis and carnica test colonies and therefore, it is supposed to be characteristic to systematical levels of honeybee species and higher.

We also showed that most test colonies, which had been disturbed by the combined stimulation in the mp-regime, strongly enhanced their basic reactivity to purely mechanical stimuli and regarding the arousal state in the nest (Stabentheiner et al 1987, 2002, 2007). This finding confirms the idea that the initial exposure to alarm pheromones alone must have informed the colony without arousing it (to release soldier bees or to retreat to the nest). To arouse a colony that way, other kinds of stimuli have to be chosen or paired with alarm pheromone. This finding makes sense in the co-evolutionary context of predator-prey arms race: For honeybees, it seems that there was no need to evolve an alarm scent without addressing any target. To utilize the high-energy protein and sugar resources in a honeybee nest, a predator has to approach or even enter the nest. The colony should adaptively respond to predators, by repelling (Kastberger et al. 2007), heat-balling (Ono et al 1987, 1995; Ken et al. 2005) or eventually stinging it. Thus, scent-marked by alarm pheromones, a predator is easily targeted by newly recruited flying guards. 
There are ambiguous reports how foraging activity in honeybees does influence defensiveness. The main opinion is that colony defence is associated with the cohort of foragers, from which entrance guards and soldier bees (Breed et al 2004) can be quickly recruited as flying defenders. This 'foragers-are-recruited-for-defence' hypothesis is plausible due to the following findings: (a) Younger bees, less than 1 week old, produce little or no IPA; bees 2-3 weeks old show maximum amounts (Boch and Shearer 1966, 1967, 1971; Whiffler et al. 1988). (b) The alerting and defence of the colony is undertaken by bees who have just reached foraging age (Free 1961; Collins and Rothenbuhler 1978). (c) The period of guard duty is not confined to a definite stage in the life history, nor is it necessarily a full-time occupation (Collins et al. 1987). Guard bees have been observed foraging and robbing during off-duty periods and presumably, they perform various tasks within the hive (Crewe and Hastings 1976; Crewe 1977). (d) In African honeybees, defensiveness was found to correlate positively with the magnitude of the population at home, which is characteristically high around noon and early afternoon, when foraging intensity is at its daily low (Peterson 1985; Adjaloo 1991). (e) Separate analysis of foragers, entrance and flying defenders has brought even more arguments for supporting the 'foragers-are-recruited-for-defence' hypothesis. The age distribution of flying defenders and foragers overlaps broadly, some guards were proved to become foragers, although flying defenders had significantly less wear in the wings than foragers (Moore et al. 1987; Breed et al. 1990).

According to our findings, the test colonies threatened by mechanical shocks alone, split up into two defence types, m-releasers and m-retreaters; both types released fewer flying defenders and were more inclined to retreat to the nest when they foraged at a higher level. This observation matches well the 'foragers-arerecruited-for-defence' hypothesis and includes all test colonies of the three subspecies investigated. This finding let us propose that under only-mechanical stimulation (m-regime) these colonies utilize only one pool of worker bees to mobilize for either foraging or defence.

The novel aspect we found here is that the additional application of alarm pheromones in natural concentrations dramatically changes the basic response pattern for both defence types which we found for the m-regime (for a summarization of the findings, see Fig. 8). Three of the nine test colonies in our test sample $\left(s c u t_{A}, s c u t_{B}, \operatorname{cap}_{A}\right)$, all were African colonies, became particularly 'super-aggressive'. They not only released a, compared to the m-regime, increased number of flying defenders, they also increased their release of flying defenders with a rising foraging level. Therefore, we postulate that these colonies have two separate pools of worker bees, one for foraging and one for mobilising soldiers, and that the contingent of worker bees which are recruitable as soldier bees correlates in these colonies positively with the foraging state. 'Super-aggressivity' in this sense does hardly support the 'foragers-are-recruited-for-defence' hypothesis, it rather implies a colony-intrinsic division of the pools of worker bees with different work loads. Interestingly, the recruitment of foragers is likely to dominate also under these conditions the recruitment of flying defenders, but in the other way round. It violates the seemingly 'standard' concept of 'foragers-are-recruited-for-defence' of honeybee 
colonies, that only a single pool of worker bees exists from which foragers and flying defenders can be recruited. This sort of trading-off relation seems to be the 'standard' situation which has been disclosed under the m-regime in all 11 test colonies and, in six from nine colonies, even under combined stimulation.

These findings of 'super-aggressivity' and the pairness of recruitment pools fit to the reports about the defensiveness of African bees (jemenitica: El-Sarrag 1991; scutellata: Schneider and McNally 1992; adansonii: Sawadogo 1993; Woyke 1992) and Africanised bees (Otis et al. 1981; Collins et al. 1982, 1989; Villa 1988; Winston 1992). As mentioned above, the age distribution of flying defenders and foragers in African bees overlaps but it is still different, which may indicate the existence of two pools (Moore et al. 1987; Breed et al. 1990). A second argument comes from the particular defensiveness of African honeybees and the Africanized hybrids under strong nectar flows (which maximised the foraging rate). The investigated colonies responded very quickly to alarm stimuli, released greater numbers of flying defenders, and counter-attacked marauders with greater intensity (Woyke 1992, Hepburn and Radloff 1998; Schneider and McNally 1992; Sawadogo 1993).

Our findings cannot support any conclusion about subspecies-specific defence typology in honeybees, because of the paucity of test colonies investigated. However, with the exception that we have not traced any sign for "superaggressiveness" in the European test colonies, we found all other types of defence strategies in our test colonies of African and European honeybees, which is interesting insofar as our sample size of 11 test colonies of three subspecies was relatively small.

Acknowledgments The authors thank O. Winder for the support during the South African experiments, J. Ulz, M. Marek from the Styrian Bee Institute and H. Elsasser from Fladnitz im Raabtal for providing test hives, students of the Institute of Zoology of the University of Graz (summer course for ethology 2001) for experiments with Apis carnica colonies and G. Raspotnig for critical reading of the draft manuscript. We thank Trevor Hoole for permission and his kindness to do research at his Slaaikraal farm near Grahamstown. Partially granted by the Austrian Science funds (FWF) project P 13210-BIO.

Open Access This article is distributed under the terms of the Creative Commons Attribution Noncommercial License which permits any noncommercial use, distribution, and reproduction in any medium, provided the original author(s) and source are credited.

\section{References}

Adjaloo MK (1991) Foraging strategies and some morphometric characteristics of the African honeybee Apis mellifera adansonii in the humid forest environment. Thesis, University of Kumasi, Ghana

Blum MS (1969) Alarm pheromones. A Rev Ent 14:57-80

Boch R, Shearer DA (1966) Iso-pentyl acetate in stings of honeybees of different ages. J Apic Res 5:65-70

Boch R, Shearer DA (1967) 2-heptanone and 10-hydroxy-trans-dec-2-enoic acid in the mandibular glands of worker honeybees of different ages. Z Vergl Physiol 54:1-11

Boch R, Shearer DA (1971) Chemical releasers of alarm behaviour in the honeybee Apis mellifera. J Insect Physiol 17:2277-2285

Boch R, Rothenbuhler WC (1974) Defensive behaviour and production of alarm pheromone in honeybees. J Apic Res 13:217-221 
Brandeburgo MM, Goncalves LS, Kerr WE (1982) Effects of Brazilian climatic conditions upon the aggressiveness of Africanized colonies of honeybees. In: Jaisson P (ed) Social insects in the tropics. Presse de l'Université Paris Nord I, Paris, pp 256-280

Breed MD, Robinson GE, Page RE (1990) Division of labor during honey bee colony defence. Behav Ecol Sociobiol 27:395-401

Breed MD, Smith TA, Torres A (1992) Role of guard honey bees (Hymenoptera: Apidae) in nestmate discrimination and replacement of removed guards. Ann Entomol Soc Am 85:633-637

Breed MD, Guzman-Novoa E, Hunt GJ (2004) Defensive behavior of honey bees: organization, genetics, and comparisons with other bees. Ann Rev Ent 49:271-298

Collins AM (1979) Genetics of the response of the honeybee to an alarm chemical, isopentyl acetate. J Apic Res 18:285-291

Collins AM (1981) Effects of temperature and humidity on honeybee response to alarm pheromones. J Apic Res 20:13-18

Collins AM, Rothenbuhler C (1978) Laboratory test of the response to an alarm chemical, isopentyl acetate, by Apis mellifera. Ann Ent Soc Am 71:906-909

Collins AM, Kubasek KJ (1982) Field test of honey bee (Hymenoptera: Apidae) colony defensive behaviour. Ann Ent Soc Am 75:383-387

Collins AM, Rinderer TE (1985) Effect of empty comb on defensive behaviour of honeybees. J Chem Ecol 11:333-338

Collins AM, Rinderer TE, Habro JR, Bolten AB (1980) A model of honeybee defensive behaviour. J Apic Res 19:224-231

Collins AM, Rinderer TE, Habro JR, Bolten AB (1982) Colony defence by Africanized and European honeybees. Science 218:72-74

Collins AM, Rinderer TE, Habro JB, Brown MA (1984) Heritabilities and correlations for several characters in the honey bee. J Heredity 75:135-140

Collins AM, Rinderer TE, Tucker KW, Pesante D (1987) Response to alarm pheromone by European and Africanized honeybees. J Apic Res 24:217-223

Collins AM, Rinderer TE, Tucker KW (1988) Colony defence of two honeybee types and their hybrid 1 naturally mated queens. J Apic Res 27:137-140

Collins AM, Rinderer TE, Daly HV, Harbo JR, Pesante DG (1989) Alarm pheromone production by two honeybee Apis mellifera types. J Chem Ecol 115:1747-1756

Crewe RM (1977) Pheromones and the colonial defensive behaviour of Apis mellifera adansonii. In: Fletcher DJC (ed) African Bees. Apimondia, Pretoria, pp 177-183

Crewe RM, Hastings H (1976) Production of pheromones by workers of Apis mellifera adansonii. J Apic Res 15:149-156

Drum NH, Rothenbuhler WC (1984) Effect of temperature on non-stinging aggressive responses of worker honeybees to diseased and healthy bees. J Apic Res 23:82-87

El-Sarrag MSA (1991) Morphological and biological studies on Sudanese honeybees Apis mellifera. Thesis, University of Cairo, Egypt

Free JB (1961) The stimuli releasing the stinging response of honeybees. Anim Behav 9:193-196

Hepburn HR, Crewe RM (1991) Portrait of the Cape honeybee Apis mellifera capensis. Apidologie 22:567-580

Hepburn HR, Radloff SE (1998) Honeybees of Africa. Springer, Berlin

Kastberger G, Sharma DK (2000) The predator-prey interaction between blue-bearded bee eaters Nyctyornis athertoni and giant honeybees Apis dorsata. Apidologie 31:727-736

Kastberger G, Schmelzer E, Kranner I (2008) Social waves in Giant honeybees repel hornets. PLoS ONE 3(9):e3141

Ken T, Hepburn HR, Radkloff SE, Yusheng Y, Yiqiu L, Danyin Z, Neumann P (2005) Heat-balling wasps by honeybees. Naturwissenschaften 92:492-495

Kerr WE (1967) The history of the introduction of African bees in Brazil. SA Bee J 39:3-5

Maschwitz U (1963) Gefahrenalarmstoffe und Gefahrenalarmierung bei sozialen Hymenopteren. Z Vergl Physiol 47:596-655

Maschwitz U (1964) Alarm substances and alarm behaviour in social hymenoptera. Nature 204:324-327

Michener CD (1975) The Brazilian bee problem. Ann Rev Ent 20:399-416

Moore AJ, Breed MD, Moor MJ (1987) The guard honey bee: ontogeny and behavioural variability of workers performing a specialized task. Anim Behav 35:1156-1167

Moritz RFA, Southwick EE (1992) Bees as superorganisms. Springer, Berlin

Moritz RFA, Southwick EE, Harbo JR (1987) Genetic analysis of defensive behaviour of honeybee colonies Apis mellifera $\mathrm{L}$. in a field test. Apidologie 18:27-42 
Ono M, Okada I, Sasaki M (1987) Heat production by balling in the Japanese honeybee, Apis cerana japonica as a defensive behavior against the hornet, Vespa simillima xanthoptera (Hymenoptera: Vespidae). Experientia 43:1031-1032

Ono M, Igarashi T, Ohno E, Sasaki M (1995) Unusual thermal defence by a honeybee against mass attack by hornets. Nature 377:334-336

Otis G, Winston ML, Taylor OR (1981) Engorgement and dispersal of Africanized honeybee swarms. J Apic Res 20:3-12

Page RE, Robinson GE, Fondryk MK, Nasr ME (1995) Effects of worker genotypic diversity on honey bee colony development and behaviour Apis mellifera L. Behav Ecol Sociobiol 36:387-396

Peterson M (1985) African honeybees in east and west Africa, and Africanized bees in Venezuela: some observations on behaviour. In: Proc. 3rd Int. Conf. Apic. Trop. Clim., Nairobi, Kenya, pp 109-111

Ruttner F (1988) Biogeography and taxonomy of honeybees. Springer, Berlin

Sawadogo M (1993) Contribution a l'étude du cycle des miellées et du cycle biologique annuel des colonies d'abeilles Apis mellifica adansonii Lat. a l'ouest du Burkina Faso, Thesis, Université de Ouagadougou, Burkina Faso

Schneider SS, McNally LC (1992) Colony defence in the African honey bee in Africa Hymenoptera: apidae. Env Ent 21:1362-1370

Schua L (1952) Untersuchungen über den Einfluss meteorologischer Elemente auf das Verhalten der Honigbienen Apis mellifica. Z Vergl Physiol 34:258-277

Seeley TD, Seeley RH, Aratanakul P (1982) Colony defence strategies of the honeybees in Thailand. Ecol Monogr 52:43-63

Southwick EE, Moritz RFA (1987) Effects of meteorological factors on defensive behaviour of honey bees. Int J Biometeor 31:256-265

Stabentheiner A, Schmaranzer S (1987) Thermographic determination of body temperatures in honey bees and hornets: calibration and applications. Thermology 2(4):563-572

Stabentheiner A, Kovac H, Schmaranzer S (2002) Honeybee nestmate recognition: the thermal behaviour of guards and their examinees. J Exp Biol 205:2637-2642

Stabentheiner A, Kovac H, Schmaranzer S (2007) Thermal behaviour of honeybees during aggressive interactions. Ethology 113:1-12

Stort AC (1974) Genetic study of aggressiveness of two subspecies of Apis mellifera in Brazil. J Apic Res $13: 33-38$

Stort AC (1975a) Genetic study of aggressiveness of two subspecies of Apis mellifera in Brazil. 2. Time at which the first sting reached the leather ball. J Apic Res 14:171-175

Stort AC (1975b) Genetic study of aggressiveness of two subspecies of Apis mellifera in Brazil. V. Number of stings in the leather ball. J Kans Ent Soc 48:381-387

Villa JD (1988) Defensive behaviour of Africanized and European honeybees at two elevations in Colombia. J Apic Res 27:141-145

Whiffler LA, Druesedau MUH, Crewe RM, Hepburn HR (1988) Defensive behaviour and the division of labour in the African honeybee Apis mellifera scutellata. J Comp Physiol A 163:401-411

Winston ML (1987) The biology of honey bees. Havard University Press, Cambridge

Winston ML (1992) Killer bees. The Africanized honey bee in the Americas. Harvard University Press, Cambridge

Woyke J (1992) Diurnal and seasonal variation in defensive behaviour of African bees Apis mellifera adansonii in Ghana. Apidologie 23:311-322 